\title{
GETTING IN TOUCH - SOCIAL STATUS PREDICTS PHYSICAL INTERACTION IN CLASSROOMS
}

\author{
Stephanie J. Eder1,2, Elisabeth Oberzaucher ${ }^{2,3}$ \\ 1Department for Basic Psychological Research and Research Methods, University of Vienna, Austria \\ 2 Urban Human, Vienna, Austria \\ ${ }^{3}$ Faculty of Life Sciences, University of Vienna, Austria
}

\section{Stephanie.eder@univie.ac.at}

\begin{abstract}
Social interactions and hierarchical structures in classrooms are studied in a number of scientific disciplines, yet the complexity of such systems makes them hard to investigate. In the present study we explore the relationship between social status and bodily interaction, since non-verbal communication and touch play a role in most social systems, yet are poorly understood in school settings.

We developed a novel approach to assess social status in grammar school students by way of measuring the presence in others' minds: Classmates assessed their peers in intellectual, social and physical domains. Additionally, we measured the amount and nature of physical interactions among classmates during breaks in the classroom. These interactions were tracked with the help of older, trained and regularly supervised students from the same school. This peer-to-peer method generated large amounts of data over a period of two months, during which 168 students were observed repeatedly.

Results show that touching behavior is modulated by social status and sex: The amount of physical interaction with classmates increases significantly with social status. Same sex touching of intimate zones such as breasts, lap and buttocks occur more frequently among individuals of similar status as compared to touching the intimate zones of the opposite sex. The latter involves extremely high and low ranked individuals more often than same-sex interactions.

This study helps to understand formative interactions within classrooms and gives rise to new questions on the establishment and maintenance of hierarchies in peer groups.
\end{abstract}

Keywords: social interaction, classroom hierarchy, social touch, physical interaction, social status.

\footnotetext{
${ }^{*}$ Paper presented at XXIV Biennial Conference of Human Ethology 2018, in Santiago, Chile.
} 


\section{TOUCH, HIERARCHY AND SOCIAL INTERACTIONS IN CLASSROOMS}

The ambivalence and ambiguity of touches, especially when status differences and dependencies are involved, are publicly debated (Kantor, 2018; Astor, 2018).

Recently, this topic has gained attention in the context of classrooms through the initiative of a US-school to ban touches from schools altogether (The Associated Press, 2007). Other schools are merely restricting 'inappropriate' touches (Jones, 2011). It is of little surprise that measures are taken to outlaw unwanted physical interactions, but this might lead to depriving us from essential parts of our social lives: The many functions of touch not only include expression of dominance, but also affiliative interactions, such as social grooming (Lehmann, Korstjens \& Dunbar, 2007; Dunbar, 2012).

Physical interaction serves a communicative purpose in social interactions. Not only can touch convey emotions (Hertenstein, Holmes, McCullough, \& Keltner, 2009; Hertenstein, Keltner, App, Bulleit \& Jaskolka, 2006) and reflect social bonds (Suvilehto et al, 2019), it also increases persuasiveness and has positive effects on compliance (Gueguen, Jacob \& Boulbry, 2007; Gueguen \& Fischer-Lokou, 2003; Guéguen, 2002).

Social touch is known to have various physiological benefits such as a decreased heart rate and increased oxytocin levels (Heinrichs, Baumgartner, Kirschbaum, \& Ehlert, 2003; Henricson, Berglund, Maatta, Ekman \& Segesten, 2008; Light, Grewen \& Amico, 2005), and it can counteract the negative effects induced by stress, as measured with physiological and biochemical markers such as blood pressure and salivary cortisol (Grewen, Anderson, Girdler, \& Light, 2003; Ditzen, Neumann, Bodenmann, von Dawans, Turner, Ehlert \& Heinrichs, 2007). This nonverbal comforting effect of touch is more effective than the benefits obtained from verbal social support (Holt-Lunstad, Birmingham \& Light, 2008). It appears to be an innate mechanism, as lowered cortisol levels resulting from physical touch can not only be observed in adults, but also in neonatal premature infants (Neu, Laudenslager, \& Robinson, 2009). Empirical findings indicate that the positive effects of touch affect both the toucher and the one being touched (Neu et al., 2009).

Healthy touching interactions are a sign of secure dyadic attachment: Infants of depressed mothers receive less physical attention and compensate for this with selfstimulation (Herrera, Reissland, \& Shepherd, 2004). Ferber and colleagues identified affectionate, stimulating and instrumental types of caregiving touch in humans (Ferber, Feldman \& Makhoul, 2008). Caregiving touch is essential for psychological and physiological development: Children deprived of touch show developmental delays i.e. in cognitive skills (MacLean, 2003; Nelson, 2007). Not only humans, but other mammals depend on touch for healthy development, too (Harlow,1958; Gonzalez, Lovic, Ward, Wainwright \& Fleming, 2001): Early comparative studies emphasize the importance not only of mother-infant-interactions, but also of peer to peer contact in mammalian development (Harlow, Harlow, Dodsworth \& Arling, 1966; Gonzalez et al., 2001). Later experimental studies confirmed that developmental delays can indeed result from missing tactile stimulation (Scafidi, Field, Schanberg, Bauer, Vega-Lahr, Garcia, Poirier, Nystrom \& Kuhn, 1986; Gonzalez et al., 2001; Lovic \& Fleming, 2004).

Touch contributes to our healthy development and physical well-being, but can also be perceived as molesting. In much the same way, hierarchy and social status can be seen as both: an instrument to exploit group members and bring advantage to single individuals 
(Hall \& Fedigan, 1997; Cummins, 1999), or as an essential scaffold for group processes to function in a peaceful manner (Collias, 1953, Weisfeld \& Beresford, 1982). Both peer status and physical attention affect an individual's health and physiology in many species, including humans (Tamashiro, Nguyen \& Sakai, 2005; Kaplan, Manuck, Fontenot \& Mann, 2002; Ely \& Henry, 1978; Wang, Houshyar, \& Prinstein, 2006; Clutton-Brock, Hodge, Spong, Russell, Jordan, Bennett, Sharpe \& Manser, 2006; Sapolsky \& Share, 1994).

In most modern cultures, humans spend much of their developmentally critical periods in school. However, there is not much quantitative long-term research on the function and perception of physical interactions at school, mostly due to feasibility issues. The existing literature on interactions and hierarchy in classrooms is very diverse: The range of different aspects covered and the variable methods create a patchwork of insights that cannot be integrated easily into a larger context. Social interactions have mostly been studied in the context of collaborative learning and student-teacher-interaction, but not so much in unstructured social settings. Classroom status is often discussed in connection to aggression and in the context of bullying, (Jennings \& Greenberg, 2009; Garandeau, Lee, \& Salmivalli, 2014; Gest \& Rodkin, 2011; Garandeau, Ahn \& Rodkin, 2011) as well as from an evolutionary perspective (Hawley, 1999; Zwaan, Dijkstra \& Veenstra, 2013).

The present study investigates the relation between physical interactions and status in classrooms. It introduces a methodology applicable to a variety of research questions: Direct observation of physical interactions of children during morning breaks at school within a naturally formed hierarchy, which is assessed through peer nomination.

As touching behavior is a form of communication, we hypothesized that (1) the higher one's social status, the higher the active interaction frequency with one's own and the opposite sex and (2) touches to intimate areas are initiated more often by high status boys towards low status boys, whereas this would not be the case in girls.

\section{METHODS}

\section{Subjects}

Participants were 239 students aged 10-13 years from grade 5 and 6 of secondary school (119 boys, 120 girls). The sample is derived from 9 classrooms at three secondary schools in Vienna, Austria. Data of 72 participants were used to develop our model, which was then tested using the data of the remaining 167 participants.

In order to sample data on physical interaction without disrupting the school routine, 29 older students from 10th grade (aged 15-17 years) were recruited as annotators. They were trained to annotate the physical interactions of their younger schoolmates and repeatedly documented the social interactions over a period of a month as described below.

Parents or legal guardians of both participating and observing students had to sign consent forms. The study was approved by the Viennese educational authority. 


\section{Measurement of social status}

Determining which students are often the center of attention can be used to find out a social hierarchy within a group of children (Hold, 1980).

We measured how present the students are in their peers' mind via peer-nomination. Participants filled in a questionnaire in which they were asked to name classmates with outstanding social, intellectual and physical qualities: Who is your best friend?, Who is your friend?, Who is the best in class? Whom do you admire? Who is the boss? Which of the boys do most girls like? Whom do you like most? Who is particularly nice? Who is the strongest boy/girl?* Who is the smartest boy/girl?* Who is the funniest boy/girl?* (*asked separately for boys/girls).

Students had to write down the names without any list to choose from, eliminating the possibility of response bias (see Poulin \& Dishion, 2008). Participants were instructed to answer honestly and intuitively and not to answer the question if nobody came to their mind. We emphasized that there were no wrong answers and that we were interested in how they personally perceive their classmates. They wrote down their own name and named their classmates' true names, but were informed that no personal data would be stored, and evaluations would not be shared with teachers and students. To ensure anonymity, all data were number-coded for further analyses.

Each time a student was nominated, he/she received one point, regardless of the quality nominated for. The final sum for each student was used as an indicator of how present a student is in his or her peers' minds. Self-nominations were not taken into account. The only exception to the above one-point rule was the nomination as 'best friend', for which two points were awarded. The composite value of social status was determined separately for boys and girls by ranking their sum of points. The more questionnaires that are completed, the more likely it is for any given participant to be nominated. In order to control for that and to make data comparable between classes, we normalized the sum of points by dividing it by the number of questionnaires completed in that class.

This method allows one to assess which individuals are present in the social perception of their classmates and which are not in the focus of attention.

Four questions refer to social acceptance (friend/best friend/like/nice), which is widely used to determine both status and popularity (Zeleny, 1940; Coie, Dodge \& Coppotelli, 1982). The questions asking to name who is tops in something refer to an implicit hierarchy in diverse aspects (intellect/fun/strength/success with opposite sex). The question 'who ist he boss' explicitly asks who is at the top of the hierarchy.

Those who are nominated more often are more present in their peers' minds and we will refer to them as having a higher social status.

Our first analyses focused on testing the social status questionnaire for redundant questions and determining whether self- nominations reflect the peers' opinion regarding that individual's traits. Training data showed that self-nominations did not correlate with peer-nomination in the corresponding categories. Therefore we did not include them in our calculation of social status.

Some questions were correlated, but not entirely redundant in the training data. As we wanted to keep the score a quantitative measure of the all-together nomination of each student without weighting categories, we included all of them equally, assigning one point for each nomination. 
The only category where we awarded two points is the nomination as 'best friend'. As training data showed that some students named their best friend again in 'friends', but some did not, we decided to give two points to the participant in 'best friend' but no additional point for 'friends' even if she/he was mentioned there as means to remove possible inaccuracy due to different comprehension of the questions.

\section{Measurement of physical interaction}

Interactions were annotated during breaks in between lessons on an observation sheet by student observers. The interactions took place in the children's classrooms.

Annotators were instructed to record each instance of physical interaction. The annotations detailed a) the active party ('the toucher'), b) the passive party ('the one being touched'), c) the body zone the active party used and d) the body zone of the passive party that was touched. If the active and the passive party could not be reliably identified, the interaction was annotated as mutual touch. Body zones were divided in: head, breast-zone, torso, lap, buttock, hands, arms and legs.

Observers documented the duration of their observation sessions, in order to allow comparisons of data between classes.

\section{Training of the observers}

Twenty-nine grade 10 students volunteered to participate in the data collection for this study. They received a general introduction to ethology and observational methods, and were trained how to use the observational sheet on each other. This resulted in six teams of 4 to 5 students; each team was assigned to observe one class. They introduced themselves to the class they were observing. Knowledge of the participants' identity was acquired through direct interaction as well as with photos and name lists. Abbreviations were used to record the participants' identity and activity. Data entry replaced the abbreviations with number codes, and the recording sheets were destroyed to ensure anonymity of the subjects. Only the first author was privy to the key linking abbreviations to numbers.

Before starting the data collection, annotators performed test observations to ensure that their observations were identical and to allow for the participants to get used to an older student sitting in their classroom and to return to their usual behavioral routine. The whole training phase took approximately one month.

During the data recording phase in the consecutive month, observers were supervised face-to-face at least once a week and were in frequent contact with us over social media. They were instructed to immediately report any problems or uncertainties and received a prompt answer in such cases. Faulty observation sheets were discarded.

\section{Evaluation}

For each participant, we extracted the number of active touches to the same sex, passive touches from the same sex, active touches to the other sex and passive touches from the other sex, irrespective of the body zone as measure of total physical interactions. Touches to 
intimate areas such as the lap, breast-area and buttocks (actively and passively) were analyzed separately.

The longer a cohort was observed, the more likely it was for a participant to have been observed touching someone or being touched. The time-span of recording and the amount of recorded touches correlate, but different classes seem to have typical habits regarding the frequency of touching. We therefore normalized the touches of each participant dividing the number of touches per individual by the total number of recorded touches in that class, regardless of the time span.

\section{Analysis}

We analyzed the association of social status and total amount of touches with Pearson's linear correlation. As our measurement of social status is based on the mere count of peernominations, the resulting scores can be compared directly within the same class and are assumed to be interval-scaled. One-tailed statistical tests were applied.

Touches to intimate zones were analyzed for male-male, female-female and opposite-sex interactions. To analyze how often touches to individuals with higher status, same status or lower status occurred in these categories, we used Chi-square-tests.

Additionally, we calculated the difference in social status between the toucher and the one touched for each physical interaction (|number of nominations of the toucher minus number of nominations of the one being touched|) and tested for differences between the categories with one-factorial ANOVA.

To analyze what individuals are most likely to touch private areas of the opposite or same sex, we categorized them as either 'upper or lower third', 'middle third' in the status hierarchy of their classrooms or as 'extreme: lowest, second-lowest, highest or secondhighest in their classroom. We tested group differences in touching the private areas of the opposite vs. same sex with the Mann-Whitney U-test.

Questionnaire data of 72 participants from three classrooms (two schools) were used as training dataset for the measurement of social status. Together, they provided data on 102 classmates.

Data of 167 participants entered the final analyses. One class of 30 participants was only observed for 14 minutes and therefore removed from analyses. In total, 280 minutes of interactions were annotated, during which 452 touches were recorded. For the analysis of touches to the opposite sex, another class was excluded, because only one incident of touch to the opposite sex had been recorded. 


\section{RESULTS}

\section{Association between social status and physical interaction with the same sex}

Active touches to same-sex classmates correlate significantly with the number of nominations for boys, girls, and both sexes combined $\left(\mathrm{r}_{\text {boys }}(67)=0.521, \mathrm{p}<.001, \mathrm{r}_{\text {girls }}(70)=\right.$ $0.242, \mathrm{p}=.022, \mathrm{r}_{\mathrm{both}}(137)=0.371, \mathrm{p}<.001$, Table 1 ). Passive touches (frequency of being touched) by same-sex classmates correlate weakly, but significantly with the number of nominations for boys and both sexes combined, but not for girls $\left(\mathrm{r}_{\text {boys }}(67)=0.212, \mathrm{p}=.042\right.$, $\mathrm{r}_{\text {both }}(137)=0.159, \mathrm{p}=.031$, Table 1$)$.

\section{Association between social status and physical interaction with the opposite sex}

Active touches to classmates of the opposite sex correlate with the number of nominations, both sexes combined $\left(\mathrm{r}_{\text {both }}(102)=0.190, \mathrm{p}=.028\right)$. This effect is weak and is not significant when analyzing each sex separately. There is no correlation between nominations and being touched by the other sex (Table 1).

Table 1: Correlations between number of nominations and touching interactions, all participating classes combined, normed by number of touches. Active $=$ active touches, Passive $=$ passive touches, $\mathrm{N}=$ number of participants, $\mathrm{R}=$ Pearson's $\mathrm{R}$.

\begin{tabular}{|c|c|c|c|c|c|c|c|c|c|c|c|c|c|c|}
\hline & \multicolumn{7}{|c|}{ Interaction with the same sex } & \multicolumn{7}{|c|}{ Interaction with the opposite sex } \\
\hline & \multicolumn{2}{|c|}{ Active } & \multicolumn{2}{|c|}{ Passive } & \multicolumn{3}{|l|}{ Both } & \multicolumn{2}{|c|}{ Active } & \multicolumn{2}{|c|}{ Passive } & \multicolumn{3}{|l|}{ Both } \\
\hline & $\mathrm{R}$ & $\mathrm{p}$ & $\mathrm{R}$ & $\mathrm{p}$ & $\mathrm{R}$ & $\mathrm{p}$ & $\mathrm{N}$ & $\mathrm{R}$ & $\mathrm{p}$ & $\mathrm{R}$ & $\mathrm{p}$ & $\mathrm{R}$ & $\mathrm{p}$ & $\mathrm{N}$ \\
\hline $\begin{array}{l}\text { Both } \\
\text { sexes }\end{array}$ & .371 & $<.001$ & .159 & .031 & .306 & $<.001$ & 137 & .190 & .028 & .069 & .245 & .143 & .075 & 102 \\
\hline Boys & .521 & $<.001$ & .212 & .042 & .451 & $<.001$ & 67 & .179 & .103 & -.103 & .234 & .058 & .342 & 52 \\
\hline Girls & .242 & .022 & .119 & .163 & .200 & .049 & 70 & .210 & .072 & -193 & .090 & .219 & .064 & 50 \\
\hline
\end{tabular}

\section{Touches to intimate zones}

Same-sex touching of private areas such as breasts, lap and buttocks seem to occur more frequently among girls of similar status and boys differing in the amount of nominations, but this effect remains below significance. The difference in social status between the active and passive party is significantly larger for touches to the opposite sex than in both malemale and female-female interactions, which occur more often between individuals of similar status $(\mathrm{F}(632,136)=4.644, \mathrm{p}=0.023)$. This means that in same-sex interactions, touches to intimate zones occur more often among individuals of similar status, whereas touches to intimate zones of the opposite sex occur more often between individuals differing in social status. 
Individuals of especially low or especially high ('extreme') status were more often involved in touches to the intimate zones of the opposite sex than in intimate touching within the same $\operatorname{sex}(\mathrm{U}(\mathrm{n} 1=15, \mathrm{n} 2=7)=18.5, \mathrm{p}=0.014)$.

\section{Post-hoc analysis}

Post-hoc analysis focused on identifying how the individual classes contributed to our final data set.

Only two individual classes show significant correlations between the number of nominations ('status') and both active touches and active and passive physical interactions combined in same sex dyads. In another class, the effect remains below significance but contributes to the main effect. Two classes, however, show almost no correlation at all between status and physical interaction. (Table 2a,b)

The rather small effect size of the correlation between number of nominations and active touches to classmates of the opposite sex (Table 1) results from strong effects in some classrooms and no correlations in others (Table 2a,b). Classrooms differ strongly in the overall frequency of physical interactions: On average, 15 touches were recorded within 10 minutes, whereas the highest frequency of interaction recorded in a classroom is 26.7 touches (class I), the lowest is 6.6 touches within the same time span (class G).

In general, the main effect (correlation between number of nominations and number of active touches) is more pronounced in boys: If analyzed separately only for boys in each class, the correlations are higher and more often significant (Table 1).

Table 2a: Correlations between number of nominations and touching interactions with the same sex for each classroom separately, normed by number of touches. Active $=$ active touches, Passive $=$ passive touches, $\mathrm{N}=$ number of participants, $\mathrm{n}=$ number of touches, $\mathrm{R}=$ Pearson's R.

\begin{tabular}{|c|c|c|c|c|c|c|c|c|}
\hline $\begin{array}{l}\text { Both } \\
\text { sexes }\end{array}$ & Active & & Passiv & & Both & & & \\
\hline Class & $\mathrm{R}$ & $\mathrm{p}$ & $\mathrm{R}$ & $\mathrm{p}$ & $\mathrm{R}$ & $\mathrm{p}$ & $\mathrm{N}$ & $\mathrm{n}$ \\
\hline $\mathrm{E}$ & .089 & .339 & -.067 & .378 & .025 & .455 & 24 & 126 \\
\hline $\mathrm{F}$ & .786 & $<.001$ & .335 & .025 & .696 & $<.001$ & 35 & 49 \\
\hline G & -.069 & .369 & -.021 & .459 & -.048 & .408 & 26 & 101 \\
\hline $\mathrm{H}$ & .578 & .001 & .398 & .018 & .592 & $<.001$ & 28 & 117 \\
\hline I & -.018 & .469 & -.251 & .118 & -.164 & .222 & 24 & 144 \\
\hline
\end{tabular}


Table 2b: Correlations between number of nominations and touching interactions with the opposite sex for each classroom separately, normed by number of touches. Active $=$ active touches, Passive $=$ passive touches, $\mathrm{N}=$ number of participants, $\mathrm{n}=$ number of touches, $\mathrm{R}=$ Pearson's R.

Interaction with the opposite sex

\begin{tabular}{|c|c|c|c|c|c|c|c|c|}
\hline $\begin{array}{l}\text { Both } \\
\text { sexes }\end{array}$ & Active & & Passiv & & Both & & & \\
\hline Class & $\mathrm{R}$ & $\mathrm{p}$ & $\mathrm{R}$ & $\mathrm{p}$ & $\mathrm{R}$ & $\mathrm{p}$ & $\mathrm{N}$ & $\mathrm{n}$ \\
\hline $\mathrm{E}$ & .433 & .019 & .228 & .278 & .231 & .139 & 24 & 27 \\
\hline $\mathrm{F}$ & - & - & - & - & - & - & 35 & - \\
\hline G & -.224 & .136 & .094 & .324 & -.060 & .386 & 26 & 16 \\
\hline $\mathrm{H}$ & .502 & .003 & -.207 & .145 & .223 & .127 & 28 & 17 \\
\hline I & .334 & .055 & .273 & .098 & .323 & .062 & 24 & 61 \\
\hline
\end{tabular}

\section{DISCUSSION}

The aim of this study was to investigate the relation between social status and physical interaction in classrooms by combining an observational approach and peer nomination. Results show that social status correlates with the frequency of both active touching and being touched in interactions in same sex dyads, but only with the frequency of active touching in mixed sex dyads, supporting our hypothesis.

Statistically, social status was defined as the independent variable in our analyses, but most probably the causal relation is bi-directional: Physical interactions serve the purpose to foster and maintain social relationships and thus are an important means to secure social status (Hall, 1996; Dodge, 1983; Schino, 2001). Also, individuals of higher social status are more likely to interact with others - more touching might simply reflect more interaction in general (see Weisfeld \& Dillon, 2012). This points to the importance of physical interaction in maintaining relationships and possibly finding friends and allies, much in the way it has been reported for other species: Touches are an important signal of bonding and belonging in humans and other animals (de Waal, 1988; Dunbar, 2012, Fields 2010).

Contrary to our second hypothesis, there is no sex-specific relationship between social status and touching of intimate zones of the same sex. However, explorative analyses showed that status matters in same-sex dyads in a more complex way: Other than in mixedsex dyads, where touching of the intimate areas occurs more often if they differ highly in status, intimate touches occur more often in same-sex dyads if they have a similar status. Interestingly, touches to the intimate areas of the opposite sex are often initiated by individuals of either extremely high or extremely low status. These results suggest different mechanisms underlying the touching of intimate zones from those underlying other physical interactions. Touches to intimate zones from high-ranking individuals might also 
serve a completely different function than if the toucher has a very low social status: The former might use these physical interactions to express their dominance, whereas the latter might use touches to intimate zones as an extreme measure to gain attention.

The fact that overall, the main effect is more pronounced in boys than in girls throughout all classrooms could reflect the assumption that boys are more likely to work out dominance hierarchies within their social networks (Omark, Omark \& Edelman, 1975, Savin-Williams, 1979). However, there is empirical support for the idea that female status hierarchies are equally important (Weisfeld, Bloch \& Bloch, 1984; Gest, Davidson, Moody \& Welsh, 2007). Therefore we assume that social status might be expressed differently in boys and girls. In addition, touch can convey many different messages.

Especially at the transition from primary to secondary school, which occurs in Austria around the age of 10, social relationships have to be re-established (Pellegrini \& Long, 2002). Our subjects, aged 10 to 13 years, were not only observed shortly after this transition, but also very shortly before the onset of puberty around the age of 13, probably the last time in their life-span where contacts to the opposite sex are relatively seldom and same-sex mates are preferred (La Freniere, Strayer \& Gauthier, 1984). The earlier onset of puberty in girls might lead to more restraint in physical interactions, and could also account for the less pronounced effects in girls. Given the age of the subjects, the observed cross-sex interactions are likely relatively novel for the participants and do not occur on a daily basis, especially those to intimate zones, which is also reflected by the small percentage they constitute within all interactions observed in our dataset (4.9\%). Those interactions are most probably not romantic, but reflect other motivations, such as to distinguish oneself from the group by doing something unusual and courageous. While regular touching interactions might help to strengthen the social bonds and thereby elevate the social status of the interacting parties, doing something outstanding such as touching intimate zones of the opposite sex might elevate social status of the toucher in the eyes of the observers. This might also be a reason that not only individuals of extremely high status, but also those with an extremely low status are more likely to touch the intimate zones of the opposite sex, since those at the very bottom of the social hierarchy have nothing to lose but much to gain.

Our results show that physical interactions in classrooms occur frequently and spontaneously, but not randomly, as specific patterns can be observed. Even though status and hierarchy are often associated with unwanted social interactions such as bullying (Garandeau et al., 2014, Garandeau et al., 2011), touching interactions are associated with reduced aggression in two cross-cultural studies (Field 1999a; Field 1999b) and in animal models (Suomi, 1984 as cited in Field, 2010).

Social status is not necessarily connected to aggression. Overall, social status in Austrian classrooms seems to correlate positively with the amount of touching interactions, although the pattern for touching intimate zones differs from that of regular touching interactions. We show that touching is a frequent, status-related interaction in classrooms that might be important to establish relationships and friendships. Therefore, our results suggest that more physical contact might mediate some of the positive effects on physical well-being obtained from higher status.

This study presents a novel approach to the complex matter of social interactions and hierarchy in classrooms. As such, results need to be viewed as a first step towards understanding this behavior, inspiring in-depth investigation and interpretation in the light of an evolutionary framework. The lack of standardization of the environmental conditions 
as is typical for any ecologically valid field study pose a limit to the conclusions drawn from our findings. The use of non-professional observers could be the source of decreased reliability. The purely quantitative approach to physical interactions, without taking into account how they are intended and perceived, could miss the nuance of touching behavior.

In the present study, we focused on the initiation of physical interaction, the next interesting question will be how the interaction continues: Is the touch reciprocated? Can touches be classified as welcome and unwelcome (i.e. through assessing the emotional response of the child who is touched)? Are touches by high-ranking individuals appreciated more? Does status difference affect the appreciation of intimate touches differently from overall physical interaction? How do responses to unwelcome touches covary with status of the toucher and/or status differences?

We hope that our direct and easy to modify methodological approach facilitates future research and thus helps to compare findings from different scientific fields. The doubtlessly great importance of touching among peers, especially in developmentally critical periods, warrants further investigation and certainly speaks against a ban of physical interactions at schools.

\section{REFERENCES}

Astor, M. (2018, April 26).The Times's Reporting on Harvey Weinstein Will Get Movie Treatment. Retreived from: www.nytimes.com/2018/04/26/movies/new-york-times-weinsteinmovie.html

Coie, J. D., Dodge, K. A., \& Coppotelli, H. (1982). Dimensions and types of social status: A crossage perspective. Developmental Psychology, 18(4), 557. DOI

Clutton-Brock, T. H., Hodge, S. J., Spong, G., Russell, A. F., Jordan, N. R., Bennett, N. C., ... Manser, M. B. (2006). Intrasexual competition and sexual selection in cooperative mammals. Nature, 444(7122), 1065. DOI

Collias, N. E. (1953). Social behavior in animals. Ecology, 34(4), 810-811. DOI

Cummins, D. D. (1999). Cheater detection is modified by social rank: The impact of dominance on the evolution of cognitive functions. Evolution and Human Behavior, 20(4), 229-248. DOI

Ditzen, B., Neumann, I. D., Bodenmann, G., von Dawans, B., Turner, R. A., Ehlert, U., \& Heinrichs, M. (2007). Effects of different kinds of couple interaction on cortisol and heart rate responses to stress in women. Psychoneuroendocrinology, 32(5), 565-574. DOI

Dodge, K. A. (1983). Behavioral antecedents of peer social status. Child Development, 1386-1399. DOI

Dunbar, R. I. (2010). The social role of touch in humans and primates: behavioural function and neurobiological mechanisms. Neuroscience \& Biobehavioral Reviews, 34(2), 260-268. DOI

Ely, D. L., \& Henry, J. P. (1978). Neuroendocrine response patterns in dominant and subordinate mice. Hormones and Behavior, 10(2), 156-169. DOI

Ferber, S. G., Feldman, R., \& Makhoul, I. R. (2008). The development of maternal touch across the first year of life. Early Human Development, 84(6), 363-370. DOI

Field, T. (1999a). Preschoolers in America are touched less and are more aggressive than preschoolers in France. Early Child Development and Care, 151(1), 11-17. DOI 
Field, T. (1999b). American adolescents touch each other less and are more aggressive toward their peers as compared with French adolescents. Adolescence, 34(136), 753.

Field, T. (2010). Touch for socioemotional and physical well-being: A review. Developmental Review, 30(4), 367-383. DOI

Garandeau, C. F., Ahn, H. J., \& Rodkin, P. C. (2011). The social status of aggressive students across contexts: The role of classroom status hierarchy, academic achievement, and grade. Developmental Psychology, 47(6), 1699. DOI

Garandeau, C. F., Lee, I. A., \& Salmivalli, C. (2014). Inequality matters: Classroom status hierarchy and adolescents' bullying. Journal of Youth and Adolescence, 43(7), 1123-1133. DOI

Gest, S. D., Davidson, A. J., Rulison, K. L., Moody, J., \& Welsh, J. A. (2007). Features of groups and status hierarchies in girls' and boys' early adolescent peer networks. New Directions for Child and Adolescent Development, 2007(118), 43-60. DOI

Gest, S. D., \& Rodkin, P. C. (2011). Teaching practices and elementary classroom peer ecologies. Journal of Applied Developmental Psychology, 32(5), 288-296. DOI

Gonzalez, A., Lovic, V., Ward, G. R., Wainwright, P. E., \& Fleming, A. S. (2001). Intergenerational effects of complete maternal deprivation and replacement stimulation on maternal behavior and emotionality in female rats. Developmental Psychobiology, 38(1), 11-32. DOI

Grewen, K. M., Anderson, B. J., Girdler, S. S., \& Light, K. C. (2003). Warm partner contact is related to lower cardiovascular reactivity. Behavioral Medicine, 29(3), 123-130. DOI

Guéguen, N. (2002). Status, apparel and touch: their joint effects on compliance to a request. North American Journal of Psychology, 4(2), 279-286.

Guéguen, N., Jacob, C., \& Boulbry, G. (2007). The effect of touch on compliance with a restaurant's employee suggestion. International Journal of Hospitality Management, 26(4), 1019-1023. $\underline{\mathrm{DOI}}$

Guéguen, N., \& Fischer-Lokou, J. (2003). Tactile contact and spontaneous help: An evaluation in a natural setting. The Journal of Social Psychology, 143(6), 785-787. DOI

Hall, J. A. (1996). Touch, status, and gender at professional meetings. Journal of Nonverbal Behavior, 20(1), 23-44. DOI

Hall, C. L., \& Fedigan, L. M. (1997). Spatial benefits afforded by high rank in white-faced capuchins. Animal Behaviour, 53(5), 1069-1082. DOI

Harlow, H. F. (1958). The nature of love. American Psychologist, 13(12), 673. DOI

Harlow, H. F., Harlow, M. K., Dodsworth, R. O., \& Arling, G. L. (1966). Maternal behavior of rhesus monkeys deprived of mothering and peer associations in infancy. Proceedings of the American Philosophical Society, 110(1), 58-66.

Hawley, P. H. (1999). The ontogenesis of social dominance: A strategy-based evolutionary perspective. Developmental Review, 19(1), 97-132. DOI

Heinrichs, M., Baumgartner, T., Kirschbaum, C., \& Ehlert, U. (2003). Social support and oxytocin interact to suppress cortisol and subjective responses to psychosocial stress. Biological Psychiatry, 54(12), 1389-1398. DOI

Henricson, M., Berglund, A. L., Määttä, S., Ekman, R., \& Segesten, K. (2008). The outcome of tactile touch on oxytocin in intensive care patients: a randomised controlled trial. Journal of Clinical Nursing, 17(19), 2624-2633. DOI

Herrera, E., Reissland, N., \& Shepherd, J. (2004). Maternal touch and maternal child-directed speech: effects of depressed mood in the postnatal period. Journal of Affective Disorders, 81(1), 29-39. DOI

Hertenstein, M. J., Holmes, R., McCullough, M., \& Keltner, D. (2009). The communication of emotion via touch. Emotion, 9(4), 566. DOI

Hertenstein, M. J., Keltner, D., App, B., Bulleit, B. A., \& Jaskolka, A. R. (2006). Touch communicates distinct emotions. Emotion, 6(3), 528. DOI 
Hold, B. C. (1980). Attention-structure and behavior in G/wi San children. Ethology and Sociobiology, 1(4), 275-290. DOI

Holt-Lunstad, J., Birmingham, W. A., \& Light, K. C. (2008). Influence of a "warm touch" support enhancement intervention among married couples on ambulatory blood pressure, oxytocin, alpha amylase, and cortisol. Psychosomatic Medicine, 70(9), 976-985. DOI

Jennings, P. A., \& Greenberg, M. T. (2009). The prosocial classroom: Teacher social and emotional competence in relation to student and classroom outcomes. Review of Educational Research, 79(1), 491-525. DOI

Jones, M. (2011, October 11): School bans 'inappropriate' touching. Retreived from: https:// www.iol.co.za/capetimes/news/school-bans-inappropriate-touching-1154784

Kantor, J. (2018, March 23). \#MeToo Called for an Overhaul. Are Workplaces Really Changing?. Retreived from: www.nytimes.com/2018/03/23/us/sexual-harassment-workplaceresponse.html

Kaplan, J. R., Manuck, S. B., Fontenot, M. B., \& Mann, J. J. (2002). Central nervous system monoamine correlates of social dominance in cynomolgus monkeys (Macaca fascicularis). Neuropsychopharmacology, 26(4), 431-443. DOI

La Freniere, P., Strayer, F. F., \& Gauthier, R. (1984). The emergence of same-sex affiliative preferences among preschool peers: A developmental/ethological perspective. Child Development, 1958-1965. DOI

Lehmann, J., Korstjens, A. H., \& Dunbar, R. I. M. (2007). Group size, grooming and social cohesion in primates. Animal Behaviour, 74(6), 1617-1629. DOI

Light, K. C., Grewen, K. M., \& Amico, J. A. (2005). More frequent partner hugs and higher oxytocin levels are linked to lower blood pressure and heart rate in premenopausal women. Biological Psychology, 69(1), 5-21. DOI

Lovic, V., \& Fleming, A. S. (2004). Artificially-reared female rats show reduced prepulse inhibition and deficits in the attentional set shifting task-reversal of effects with maternal-like licking stimulation. Behavioural Brain Research, 148(1-2), 209-219. DOI

MacLean, K. (2003). The impact of institutionalization on child development. Development and Psychopathology, 15(4), 853-884. DOI

Nelson, C. A. (2007). A neurobiological perspective on early human deprivation. Child Development Perspectives, 1(1), 13-18. DOI

Neu, M., Laudenslager, M. L., \& Robinson, J. (2009). Coregulation in salivary cortisol during maternal holding of premature infants. Biological Research for Nursing, 10(3), 226-240. DOI

Omark, D. R., \& Edelman, M. S. (1975). A comparison of status hierarchies in young children: An ethological approach. Information (International Social Science Council), 14(5), 87-107. DOI

Pellegrini, A. D., \& Long, J. D. (2002). A longitudinal study of bullying, dominance, and victimization during the transition from primary school through secondary school. British Journal of Developmental Psychology, 20(2), 259-280. DOI

Poulin, F., \& Dishion, T. J. (2008). Methodological issues in the use of peer sociometric nominations with middle school youth. Social Development, 17(4), 908-921. DOI

Sapolsky, R. M., \& Share, L. J. (1994). Rank-related differences in cardiovascular function among wild baboons: Role of sensitivity to glucocorticoids. American Journal of Primatology, 32(4), 261-275. DOI

Savin-Williams, R. C. (1979). Dominance hierarchies in groups of early adolescents. Child Development, 923-935. DOI

Scafidi, F. A., Field, T. M., Schanberg, S. M., Bauer, C. R., Vega-Lahr, N., Garcia, R., Poirier, J., Nystrom, G., \& Kuhn, C. M. (1986). Effects of tactile/kinesthetic stimulation on the clinical course and sleep/wake behavior of preterm neonates. Infant Behavior and Development, 9(1), 91-105. DOI 
Schino, G. (2001). Grooming, competition and social rank among female primates: a metaanalysis. Animal Behaviour, 62(2), 265-271. DOI

Suvilehto, J. T., Nummenmaa, L., Harada, T., Dunbar, R. I., Hari, R., Turner, R., ... \& Kitada, R. (2019). Cross-cultural similarity in relationship-specific social touching. Proceedings of the Royal Society B, 286(1901), 20190467. DOI

Tamashiro, K. L., Nguyen, M. M., \& Sakai, R. R. (2005). Social stress: from rodents to primates. Frontiers in Neuroendocrinology, 26(1), 27-40. DOI

The Associated Press (2007, June 18). School penalizes students for hugs, high-fives. Retrieved from: http://www.nbcnews.com/id/19293872/ns/us news-education/t/school-penalizesstudents-hugs-high-fives/\#.W8sZKi35zeR

Tiddi, B., Aureli, F., \& Schino, G. (2012). Grooming up the hierarchy: the exchange of grooming and rank-related benefits in a new world primate. PloS one, 7(5), e36641. DOI

De Waal, F. B. (1988). The communicative repertoire of captive bonobos (Pan paniscus), compared to that of chimpanzees. Behaviour, 106(3), 183-251. DOI

Wang, S. S., Houshyar, S., \& Prinstein, M. J. (2006). Adolescent girls' and boys' weight-related health behaviors and cognitions: Associations with reputation-and preference-based peer status. Health Psychology, 25(5), 658. DOI

Weisfeld, G. E., \& Beresford, J. M. (1982). Erectness of posture as an indicator of dominance or success in humans. Motivation and Emotion, 6(2), 113-131. DOI

Weisfeld, G. E., Bloch, S. A., \& Bloch, S. A. (1984). Possible determinants of social dominance among adolescent girls. The Journal of Genetic Psychology, 144(1), 115-129. DOI

Weisfeld, G. E., \& Dillon, L. M. (2012). Applying the dominance hierarchy model to pride and shame, and related behaviors. Journal of Evolutionary Psychology, 10(1), 15-41. DOI

Zeleny, L. D. (1940). Measurement of social status. American Journal of Sociology, 45(4), 576-582. $\underline{\mathrm{DOI}}$

Zwaan, M., Dijkstra, J. K., \& Veenstra, R. (2013). Status hierarchy, attractiveness hierarchy and sex ratio: Three contextual factors explaining the status-aggression link among adolescents. International Journal of Behavioral Development, 37(3), 211-221. DOI 